\title{
IGREJA CATÓLICA: UMA EDUCADORA AMBIENTAL?
}

\author{
Rafael Sanches Guerra $^{1}$, Tânia Mara De Bastiani ${ }^{2}$ \\ ${ }^{1}$ Publicitário e Pós-graduando do curso de especialização em Educação Ambiental - UFSM - \\ rafaelsanchesguerra@gmail.com \\ ${ }^{2}$ Licenciada em Filosofia e Pós-graduanda do curso de especialização em Educação Ambiental - UFSM - \\ taniamaradb@hotmail.com
}

\section{Resumo}

Partindo-se do tema "Fraternidade e a vida no planeta" e o lema "A criação geme com dores de parto", a campanha da fraternidade 2011 lançada pela igreja católica no Brasil destaca as consequências, principalmente, aos pobres, das mudanças climáticas. Assim, este trabalho tem como objetivo discutir se a igreja católica pode ser uma educadora ambiental e, descrever o contexto do surgimento da preocupação dela com os problemas sociais através do movimento da teologia da libertação. $O$ trabalho consiste de uma revisão bibliográfica envolvendo duas correntes da Educação Ambiental, a comportamental e a popular, onde se procura destacar em qual delas o objetivo geral, específicos e estratégias lançadas pela campanha da fraternidade 2011 se enquadram. Além disso, se procura descrever sobre a mudança de perspectiva assumida pela igreja na América Latina, desde a década de 1950, - através da I Conferência Episcopal Latino Americana (CELAM), criada em 1955, após o Congresso Eucarístico do Rio de Janeiro; do Concilio Vaticano II (1962-1965) de Roma; e, da II CELAM de Medelín (1968). Após descrever as características da Educação Ambiental comportamental e popular e o contexto de preocupação da igreja com as questões sociais, conclui-se que o objetivo geral, específicos e as estratégias da campanha da fraternidade 2011 lançados pela igreja católica brasileira se enquadram na corrente comportamental. Isto se dá, pois ela compreende a educação como agente atuante na conscientização subjetiva das pessoas quanto a sua postura em relação ao meio ambiente. Com esta postura, ela se afasta da corrente da Educação Ambiental popular, por não considerar a educação como agente formadora de indivíduos que intervém na realidade em que estão inseridos e que, portanto, a mudança de atitude em relação ao meio ambiente não depende apenas de alterações subjetivas, mas da transformação da sociedade em que vivemos. Portanto, à campanha da fraternidade 2011, ao priorizar pela conscientização dos indivíduos em relação ao meio ambiente, caracteriza a igreja católica brasileira como educadora ambiental comportamental.

Palavras-chave: Educação ambiental, Igreja católica, Campanha da Fraternidade.

\section{Introdução}

Chamado por seus primórdios de terra de Santa Cruz e tendo como primeiro ato solene uma missa, o Brasil estava após seu “descobrimento" ligado à religião católica. 
Porém, com o advento da república e a edição do decreto119-A, de 17 de janeiro de 1890, instaurou-se a separação entre a igreja e o Estado brasileiro. Depois disso, o Brasil jamais deixou de ser um Estado laico, pelo menos na teoria. Hoje, o Brasil não tem uma religião que predomine e todos os membros do nosso país são "livres" para terem suas crenças e fazerem seus cultos.

Porém, apesar da igreja católica não estar mais vinculada ao Estado e não influenciar nas suas leis, ela se preocupa com questões sociais que, muitas vezes, deveriam ser responsabilidade dele. A preocupação da igreja católica brasileira com os pobres tem contexto específico, no Brasil, destaca-se o movimento da teologia da libertação, surgido na década de 1970 em resistência ao regime militar. Hoje a preocupação da igreja com as questões sociais destaca-se através das campanhas da fraternidade lançadas anualmente através de um tema e um lema.

A campanha da fraternidade de 2011 tem como tema: Fraternidade e a Vida no Planeta e, lema: "A criação geme em dores de parto" ( $R$ m 8, 22), ela aborda as consequências que o aquecimento global e as mudanças climáticas têm para os pobres. Assim, partindo dos objetivos geral, específicos e das estratégias da campanha deste ano, este trabalho através de uma revisão bibliográfica, objetiva responder se a igreja católica brasileira pode ser considerada uma educadora ambiental.

\section{A Igreja católica e a pobreza: uma aliança através da Teologia da Libertação}

Todos os anos a Igreja católica lança a Campanha da fraternidade ${ }^{3}$ que, através de um tema e um lema, refere-se a assuntos ligados as questões sociais brasileira, priorizando problemas enfrentados, principalmente, pela população economicamente carente. Mas, será que tais preocupações da Igreja católica sempre existiram?

Grande parte da Igreja Católica no Brasil, ao longo da década de 1970, muda sua roupagem. Não mais se vestem conforme o modelo da Igreja Européia, mas tiram à batina tradicional, ou seja, se despem da cristandade que alguns chamam de "grande-instituição" e vestem-se de protetora dos pobres através da Teologia da Libertação. Nesse processo, encontram resistências por parte do setor conservador da própria Igreja e também da sociedade, especialmente daquela comprometida de alguma maneira com o regime político que havia se estabelecido no Brasil desde 1964: a ditadura civil-militar.

Os protagonistas de alguns setores da Igreja na América Latina, desde a década de 1950, através da I CELAM (Conferência Episcopal Latino Americana) criada em 1955 após o Congresso Eucarístico do Rio de Janeiro; do Concilio Vaticano II (1962-1965); e da II CELAM ocorrido em Medelín em 1968 - começaram a refletir sobre seu jeito de cultivar a religião e de manter a fé do povo. Passaram, então, a seguinte conclusão: diante de um continente pobre e miserável, decorrente da colonização ibérica e do neocolonialismo dos séculos XIX e XX, não se poderia mais manter as mesmas formas e práticas religiosas. Surgia assim a consciência, entre alguns religiosos,

\footnotetext{
${ }^{3}$ A Campanha da Fraternidade é realizada anualmente pela Igreja católica brasileira no período da quaresma (é um período de quarenta dias, começa na quarta-feira de cinzas, que antecede a festa em comemoração a ressureição de cristo, celebrada no domingo de páscoa). Cada campanha é orientada por um tema e um lema. Ela é coordenada pela Conferência Nacional dos Bispos do Brasil.
} 
de que a pobreza ou riqueza não são castigos ou prêmios de Deus, mas reflexos da estrutura de distribuição de bens. Uma parte da Igreja conclui, então, que precisava mudar ${ }^{4}$.

Além disso, tais pensamentos de transformação foram motivados pela crescente radicalização política e social na América Latina. Regan (1986, p. 27) diz que: "não obstante muitos recebessem sacolas de alimentos e até casas construídas, o número dos necessitados crescia sempre mais. A reflexão mostrou que o problema possuía causas que nenhuma quantidade de ajuda poderia conseguir resolver". Diante disso, parte da Igreja viu-se obrigada a pensar em alternativas para sua mudança sócio-política enquanto ainda fosse possível.

Diante deste contexto, surgia em 1955 a I CELAM. Essa estava destinada, segundo Rouquié:

A refletir sobre as condições específicas nas quais viveu o cristianismo nos países do continente. A centena de bispos que deu origem ao CELAM, este é o nome desse organismo, foi sensível a pressões de padres e de leigos desejosos de ver a Igreja se envolver mais diretamente nos problemas das sociedades latino-americanas (ROUQUIÉ, 1991. p. 207).

Alguns anos depois, ocorreu na Catacumba De Santa Domitila, fora de Roma, em 1962, o II Concilio do Vaticano - reunião de todos os bispos para decidirem os rumos da igreja católica inaugurado pelo papa João XXIII e encerrado em 1965 por Paulo VI. O Concilio Vaticano II foi convocado para tratar de uma crise: abismo crescente entre a Igreja e o mundo moderno. Alguns setores da Igreja queriam dialogar com o mundo, reaproximar-se dos problemas sócio-políticos do qual eles haviam se afastado.

No final do Concilio, os quarentas bispos do mundo inteiro firmaram, segundo Leonardo Boff (1996, p. 9) "um pacto da Igreja servidora e pobre, o qual se expressou por uma clara opção pelos pobres. Proclamaram a Igreja dos pobres e com os pobres". Estavam presentes neste concílio as primeiras preocupações de mudar a Igreja, estava presente, portanto, os germes da Teologia da Libertação, assim, segundo Francisco Catão:

Foi preciso que o Vaticano desse uma guinada histórica, há cem anos, para que se esboçasse e se confirmasse na igreja um movimento de reatamento do diálogo com o mundo moderno, em novas bases. Foi o Concilio do Vaticano II que, na década de sessenta, formulou finalmente essas novas bases. A teologia da libertação tem no concílio as suas raízes (CATÃO, 1986. p. 11).

Em agosto de 1968, em Medelín (Colômbia), na II Conferência Episcopal Latino Americana (CELAM), houve o amadurecimento das idéias surgidas na Conferencia do Vaticano II. No II CELAM foi tirado o que deveria ser prioridade da Igreja: os pobres, as Comunidades Eclesiais de Bases (CEB) e a libertação integral. A partir desse momento, a Teologia da Libertação ganha corpo, ou seja, nos dez anos seguintes a Medelín, ela concretiza-se através de práticas religiosas e populares que lutam contra o sistema que traz miséria e injustiça ao mundo.

Assim, influenciada, principalmente pela Conferência do Vaticano II e pela I e II CELAM, alguns setores da Igreja no Brasil, na década de 1970, também passaram a mudar de perfil e dar preferência aos pobres. Surgiu aqui, também, o movimento da Teologia da Libertação, que, por sua vez, encontrou resistência por parte do modelo político estabelecido desde 1964: o regime

\footnotetext{
${ }^{4}$ Somente alguns setores da Igreja católica optaram por mudar seu perfil e começar a dar preferência aos pobres, pois muitos religiosos católicos permaneceram conservadores, apoiavam a Ditadura Militar e, portanto, não compreendiam e não aceitavam o modelo de uma nova Igreja.
} 
militar e de alguns setores da Igreja que continuaram conservadores, pois, a Igreja católica, segundo Delgado e Passos (2003, p. 98) "não é um bloco homogêneo. Nela estão presentes práticas diferentes e mesmo contraditórias. Existem diferentes comportamentos religiosos e políticos, influenciados pela forma como seus membros se ligam às várias classes sociais".

Mas afinal de contas, o que é Teologia da Libertação? Segundo Leonardo Boff (1996) ela é filha do amor da Igreja para com os pobres sofredores deste mundo. Ele destaca sete pontos que a caracterizam: 1. É profética, pois denuncia as opressões; é pastoral, já que se interessa por transformações práticas; é militante, pois as transformações devem partir dos pobres sendo ela abertas a todas as demais. 2. Faz um apelo a consciência mundial, condenando a miséria e a exclusão social, destacando neste segundo ponto que seus membros foram perseguidas por serem adeptos a tais mudanças de perspectivas da Igreja. 3. Foi acusada de redução da fé a política e uso não-critico do marxismo. 4. O que ela suscita não interessa apenas aos que vivenciam o sonho cristão, ou seja, não é necessário ser religioso para aderir à defesa dos pobres. 5. questionou a relevância social das outras correntes teológicas. 6 . convoca para a generalidade. 7. deve servir a libertação.

Teologia da Libertação para Francisco Catão (1986, p. 80) é: "a reflexão feita à luz da fé sobre o mistério de Deus, manifestado na comunicação da salvação a todos os homens, através de sua progressiva libertação na história".

Fernanda Flores de Almeida Lovato (2007) em seu artigo "A Teologia da Libertação na América Latina e suas manifestações em Santa Maria-RS" traz o pensamento de Michael Löwy sobre a Teologia da Libertação. Assim, segundo ela, Löwy define Teologia da Libertação como sendo um corpo de textos produzidos a partir da década de 1970 por latino-americanos, especialmente teólogos. Além disso, em seu artigo ela trás oito princípios básicos e comuns, citados por Michael Löwy, ao pensamento dos teólogos da Libertação: 1. A luta contra a idolatria (a riqueza, o Mercado, o Estado, etc.); 2. A Libertação humana histórica como a antecipação da salvação final em Cristo; 3. Uma critica da teologia dualista tradicional; 4. Uma nova leitura da Bíblia, com atenção especial ao Êxodo; 5. Uma forte critica moral e social do capitalismo dependente como sistema e forma de pecado estrutural; 6. 0 uso do Marxismo como instrumento socioanalítico a fim de entender as causas da pobreza, as contradições do capitalismo e as formas de luta de classes; 7. A opção preferencial pelos pobres e a solidariedade com sua luta pela autolibertação; 8 . O desenvolvimento de base cristã entre os pobres como uma nova forma de Igreja e como alternativa ao modo de vida individualista imposto pelo sistema capitalista.

Assim, através da definição de Teologia da Libertação dada por Leonardo Boff, Francisco Catão e Michael Löwy a Teologia da Libertação pode ser interpretada como a mudança de perspectiva adotada por alguns setores da Igreja Católica. Ela adota a partir de tal movimento uma preocupação com os pobres da América Latina que por tanto tempo sobrem opressões.

Durante os regimes ditatoriais da América Latina, alguns setores da Igreja Católica lutaram em contraponto a eles. Segundo Bezerra, Oliveira e Delgado:

\footnotetext{
"A conjuntura política da década de 1960 na América Latina, com a instauração de ditaduras militares, potencializou a projeção de setores progressistas da Igreja Católica latino-americana, que se vinculou a movimentos de resistência ao autoritarismo, em prol da defesa dos direitos humanos".
}

No Brasil, a Igreja Católica tornou-se uma das possibilidades para a luta contra a ditadura onde se supunha que o Estado não interferiria. Porém, os fatos da nossa história demonstram que 
nem mesmo os setores da Igreja que se rebelaram contra o governo ditatorial passaram ilesos à repressão e até mesmo tortura de alguns de seus membros, ou seja, os fatos da história comprovam que os religiosos que optaram pelos pobres, apoiando a Teologia da Libertação e fazendo, portanto, contraponto a ditadura civil-militar sofreram conseqüências, sendo reprimidos por esse regime político.

\title{
Igreja católica: Educadora ambiental popular ou comportamental?
}

A campanha da fraternidade de 2011, através do tema: Fraternidade e a Vida no Planeta e, lema: "A criação geme em dores de parto" ( $R$ m 8, 22), aborda as consequências que o aquecimento global e as mudanças climáticas têm para os pobres. Segundo Texto base da campanha:

Órgãos da ONU já falam na existência de 50 milhões de "migrantes do clima", não podemos deixar de agir em prol de melhores condições para o nosso planeta. Sobretudo, porque, o aquecimento global e as mudanças climáticas exigirão mais sacrifícios dos mais pobres e menos protegidos. Além de quê, braços cruzados diante de tal desafio, significa irresponsabilidade tamanha para com as gerações futuras, pois ainda podemos e devemos fazer algo em prol da vida no planeta.

Como objetivo geral, a Campanha da fraternidade 2011 propõe: “Contribuir para o aprofundamento do debate e busca de caminhos de superação dos problemas ambientais provocados pelo aquecimento global e seus impactos sobre as condições da vida no planeta". Em seus objetivos específicos estão:

1. Viabilizar meios para a formação da consciência ambiental em relação ao problema do aquecimento global e identificar responsabilidades e implicações éticas; 2. Promover a discussão sobre os problemas ambientais com foco no aquecimento global; 3. Mostrar a gravidade e a urgência dos problemas ambientais provocados pelo aquecimento global e articular a realidade local e regional com o contexto nacional e planetário; 4. Trocar experiências e propor caminhos para a superação dos problemas ambientais relacionados ao aquecimento global.

Para alcançar aos objetivos a campanha da fraternidade 2011 traça as seguintes estratégias:

\begin{abstract}
1.Denunciar situações e apontar responsabilidades no que diz respeito aos problemas ambientais decorrentes do aquecimento global; 2. Propor atitudes, comportamentos e práticas fundamentados em valores que tenham a vida como referência no relacionamento com o meio ambiente; 3. Mobilizar pessoas, comunidades, Igrejas, religiões e sociedade para assumirem o protagonismo na construção de alternativas para a superação dos problemas socioambientais decorrentes do aquecimento global.
\end{abstract}

Portanto, diante do objetivo geral, específicos e das estratégias traçadas pela campanha da fraternidade 2011 podemos notar que a igreja católica além de preocupar-se com os pobres, seguindo as bases teóricas assumidas, desde a década de 1970, pela teologia da libertação, ainda demonstra sua preocupação com as questões ambientais, pois se propõe a mobilizar através da conscientização e discussões da gravidade dos problemas ambientais, no intuito de que eles sejam superados. Assim, visto que a igreja está preocupada com os problemas relacionados ao meio 
ambiente e, se propõe a conscientizar outras pessoas sobre os impactos causados pelo ser humano a natureza é possível afirmar que a Igreja católica brasileira é uma Educadora ambiental? Se sim, podemos classificá-la como Educadora ambiental popular ou Comportamental?

$\mathrm{Na}$ Educação ambiental comportamental a educação exerce papel de conscientizadora para a orientação das mudanças de hábitos considerados predatórios ao meio ambiente. Está focada, portanto, nas mudanças de atitudes dos indivíduos em particular, estando orientada na concepção de que se cada um mudar seus comportamentos diante dos recursos naturais, se cada um fizer sua parte, os impactos ao meio ambiente diminuirão. Para a Educação ambiental comportamental as crianças são consideradas o principal grupo a ser educado, pois segundo (MOURA, 2001, p. 43) "supõe-se que nelas a consciência ambiental pode ser internalizada e traduzida em comportamentos de forma mais bem sucedida do que nos adultos que, já formados, possuem um repertório de hábitos e comportamentos cristalizados e de difícil reorientação".

Na Educação ambiental popular, ao contrário da comportamental, a solução para diminuir os impactos do ser humano a natureza não está focada somente na mudança de hábitos dos indivíduos particulares, mas na transformação da sociedade que vivemos, ou seja, educação ambiental popular almeja (MOURA, 2001, p. 47) "a transformação das relações com o meio ambiente dentro de um projeto de construção de um novo ethos social, baseado em valores libertários, democráticos e solidários".

A igreja católica brasileira ao se preocupar com o meio ambiente através da campanha da fraternidade 2011, apesar de reconhecer as consequências que o aquecimento global e as mudanças climáticas têm para os pobres, em nenhum momento preza pela mudança de estrutura social que vivemos, ou seja, da superação do capitalismo que apenas se orienta em favor do lucro. Ao contrário, da concepção popular de Educação ambiental, a Igreja católica valoriza a conscientização e pretende alcançar a mudança de comportamentos dos indivíduos em relação à natureza. No item "Propostas para se diminuir o consumo pessoal" presente no texto base da campanha da fraternidade 2011 define que "a consciência de que cada um de nós é parte do problema, deve se reverter na convicção de que cada um pode pessoalmente dar o seu contributo para a diminuição das emissões de gases de efeito estufa". Portanto, a Igreja católica brasileira na campanha da fraternidade 2011, ao se preocupar com os problemas relacionados ao meio ambiente e, se propor a conscientizar sobre os impactos causados pelo ser humano a natureza pode ser considerada como uma educadora ambiental, porém, se afastada concepção popular por não questionar o modelo de sociedade que vivemos e se enquadra na concepção comportamental.

\section{Conclusão}

A adoção da doutrina neoliberal pelo Brasil, na década de 1990, faz surgir um espaço público não-estatal, ou seja, após a diminuição da influencia do estado sobre assuntos econômicos, surge um espaço com responsabilidades que devem ser assumidas por outros setores. A igreja católica brasileira, através da sua orientação de proteção aos mais pobres é uma das instituições que, da década de 1990 até hoje, preenchem o vazio deixado pelo Estado. Junto com ela, estão as ONGs, os movimentos sociais e, os projetos de responsabilidade social das empresas privadas.

Portanto, a Igreja católica brasileira, através das campanhas da fraternidade em geral e da campanha da fraternidade 2011, em específico, auxilia nas funções que deveriam ser supridas pelo Estado. No caso da campanha deste ano, a Igreja ao desenvolver o papel de educadora ambiental 
REMOA

\section{Monografias Ambientais issN: 2236-1308}

comportamental através do alerta das consequências que o aquecimento global e as mudanças climáticas têm, principalmente, aos pobres e as futuras gerações, substitui em certo nível o Estado nos aspectos de alerta de cuidado para com meio ambiente.

\section{Referências bibliográficas}

BEZERRA, Emanuela A.; DELGADO, Lucília de A. N.; OLIVEIRA, Virgílio C. (Júnior) de. "Do humanismo cristão à práxis política de oposição a ditadura: memória de uma experiência dominicana". Disponível em: www.fiocruz.br/ehosudeste/cgi/cgilua.exe/sys/start.htm?siol=16. Acesso em: 01 de set. 2011

BOFF, Leonardo; REGIDOR, José Ramos; BOFF, Clodovis. A teologia da Libertação: balanços e perspectivas. São Paulo: Ática, 1996.

CATÃO, Francisco A.C. O que é Teologia da Libertação. São Paulo: Brasiliense, 1986.

DELGADO, Lucília de A. N.; PASSOS, Mauro. "Catolicismo: direitos sociais e direitos humanos (1960-1970)". In. FERREIRA, Jorge; DELGADO, Lucília de A. N. (orgs.). O Brasil Republicano. Volume 4: O tempo da ditadura: Regime militar e movimentos sociais em fins do século XX. Rio de Janeiro: Civilização Brasileira, 2003.

LOVATO, Fernanda F. de A. "A Teologia da Libertação na América Latina e suas manifestações em Santa Maria-RS". In. QUEVEDO, Júlio; IOKOI, Zilda Márcia Grícoli (orgs.). Movimentos Sociais na América Latina: desafios teóricos em tempos de globalização. Santa Maria: MILA-CCSH, 2007.

MOURA, Carvalho, Isabel Cristina de. Qual educação ambiental? Elementos para um debate sobre educação ambiental e extensão rural. Acesso em:

http://diplomatique.uol.com.br/artigo.php?id=26\&PHPSESSID=2992afb2cd65c8594faad2ff286459fc. Disponível em: 06 de setembro de 2011.

REGAN, David. Igreja para a Libertação: Retrato pastoral da Igreja no Brasil. São Paulo: Paulinas, 1986.

ROUQUIÉ, Alain. "Igreja e Igrejas". In: O extremo-ocidente: introdução à América Latina. São Paulo: EDUSP, 1991.

Texto base da campanha da fraternidade 2011. Disponível em:

http://cnsfsc.com.br/userfiles/file/textobasecf 2011.pdf. Acesso em 06 de setembro de 2011. 